This article was downloaded by: [Lulea University of Technology]

On: 11 April 2014, At: 05:41

Publisher: Routledge

Informa Ltd Registered in England and Wales Registered Number: 1072954 Registered

office: Mortimer House, 37-41 Mortimer Street, London W1T 3J H, UK

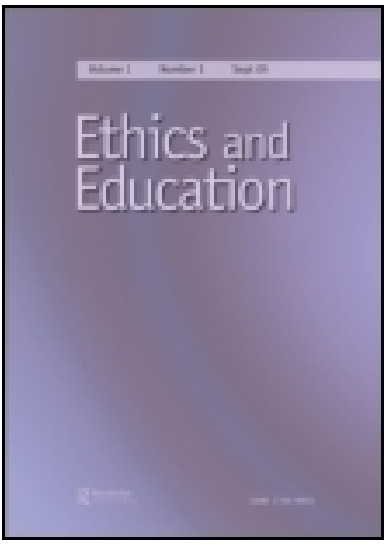

\title{
Ethics and Education
}

Publication details, including instructions for authors and

subscription information:

http:// www. tandfonline.com/loi/ ceae20

\section{Why philosophical ethics in school: implications for education in technology and in general}

\author{
Viktor Gardelli ${ }^{a}$, Eva Alerby ${ }^{\mathrm{a}} \&$ Anders Persson ${ }^{\mathrm{a}}$ \\ a Department of Arts, Communication and Education, Luleå \\ University of Technology, SE-97187 Luleå, Sweden \\ Published online: 13 Mar 2014.
}

To cite this article: Viktor Gardelli, Eva Alerby \& Anders Persson (2014) Why philosophical ethics in school: implications for education in technology and in general, Ethics and Education, 9:1, 16-28, DOI: $10.1080 / 17449642.2014 .890277$

To link to this article: http:// dx.doi.org/ 10.1080/ 17449642.2014.890277

\section{PLEASE SCROLL DOWN FOR ARTICLE}

Taylor \& Francis makes every effort to ensure the accuracy of all the information (the "Content") contained in the publications on our platform. However, Taylor \& Francis, our agents, and our licensors make no representations or warranties whatsoever as to the accuracy, completeness, or suitability for any purpose of the Content. Any opinions and views expressed in this publication are the opinions and views of the authors, and are not the views of or endorsed by Taylor \& Francis. The accuracy of the Content should not be relied upon and should be independently verified with primary sources of information. Taylor and Francis shall not be liable for any losses, actions, claims, proceedings, demands, costs, expenses, damages, and other liabilities whatsoever or howsoever caused arising directly or indirectly in connection with, in relation to or arising out of the use of the Content.

This article may be used for research, teaching, and private study purposes. Any substantial or systematic reproduction, redistribution, reselling, loan, sub-licensing, systematic supply, or distribution in any form to anyone is expressly forbidden. Terms \& Conditions of access and use can be found at http://www.tandfonline.com/page/termsand-conditions 


\title{
Why philosophical ethics in school: implications for education in technology and in general
}

\author{
Viktor Gardelli*, Eva Alerby ${ }^{1}$ and Anders Persson ${ }^{2}$ \\ Department of Arts, Communication and Education, Luleå University of Technology, SE-97187 \\ Luleå, Sweden
}

\begin{abstract}
In this article, we distinguish between three approaches to ethics in school, each giving an interpretation of the expression 'ethics in school': the descriptive facts about ethics approach, roughly consisting of teaching empirical facts about moral matters to students; the moral fostering approach, consisting of mediating a set of given values to students; and the philosophical ethics (PE) approach, consisting of critically discussing and evaluating moral issues with students. Thereafter, three influential arguments for why there ought to be ethics in school are discussed, and each argument is interpreted given each approach to ethics in school, respectively. Thereby, we evaluate which interpretation of 'ethics in school' produces the strongest arguments, and thus, which approach is best supported by these arguments. The conclusion is that there ought to be PE in school.
\end{abstract}

Keywords: ethics; moral education; technology; critical thinking; philosophy; school

\section{Introduction}

Students of today are faced with a great deal of moral choices and problems, some yet to be appraised (Johnson 2009), and still additional ones reasonably to emerge within the near future. Many of these are related to technology and technological issues and problems, such as ethical aspects of using computers and information technology (Bynum 2011), engineering ethics (Stovall 2011), or a wide range of other technological topics (Frey and Wellman 2003), some of which will be indicated below. The rapid change in the ethical landscape of technology is reflected in the fact that fields of applied ethics such as nanoethics (Johnson 2009) and cyberethics (Fuchs, Bichler, and Raffl 2009) have only recently been identified and named. There are, then, numerous reasons for holding ethics to be of great importance to education in general but also in relation to technology education in particular. For example, computers and the Internet are of great value for many of us in our private lives, but they also have a great implication on education, as claimed by, for instance, Smeds $(2008,123)$ in saying that 'computers and the Internet are $[\ldots]$ changing us, altering our relations, [and] demanding renewed strategies for education.' Among these implications for education are those for the ethical aspects of education, as once again pointed out by Smeds (2008, 133): '[E]ducational experts and

*Corresponding author. Email: viktor.gardelli@1tu.se 
practitioners [...] should create space for the ethicalities within relationships, i.e. ethical questions on how the ICT we once managed has come to manage us conceptually, institutionally and in our relationships.' Another highly important subject to be dealt with in school in relation to technology education is the ethical aspects of risk and risk management (Cerutti 2010; Papastephanou 2006), specifically in relation to technology and technological advancements (Ferretti 2010). Hence, ethics is of importance in education in relation to technology and in general. However, ethics could be dealt with in many different ways in school.

In this paper, we analyze and discuss the role of ethics in school in general and in relation to technology in particular, and scrutinize some arguments for why ethics should have the one before the others of these possible roles. In order to carry this out, a rather complex structure of the article has been adopted: we will start by making some distinctions between different positions regarding how ethics could and should be included in school. Thereafter, some arguments for why there should be ethics in school are presented and discussed. These arguments, all of which have been discussed in the context of moral education and philosophy of education in general, are then examined and evaluated in relation to the different approaches, respectively. This is a way to understand and scrutinize the arguments themselves, but at least as importantly, it is a way to better understand and evaluate the different approaches to ethics in school; if the arguments for ethics in school are strong, given a specific approach to (or interpretation of) ethics in school, then this approach to ethics in school is justified to a greater extent; if the arguments turn out weak, given a specific approach, then this approach is not as justified. Hence, our primary interest lies with discussing the different approaches to ethics in education that we will outline below, and the arguments for ethics in school that will be discussed are treated as secondary.

\section{Three approaches to ethics in school}

When using the phrase 'ethics in school, ${ }^{3}$ one could refer to many different kinds of practices. We will make a distinction between three different approaches to ethics in school, and then discuss the question 'Should there be ethics in school?' for each approach, respectively. We consider it fruitful to distinguish between what we will call 'the descriptive facts about ethics approach' (the DE approach), 'the moral fostering approach' (the MF approach), and 'the philosophical ethics approach' (the PE approach), since these all surface in the discussion about ethics in education:

(i) The DE approach: According to the DE approach to ethics in school, education should focus on the learning of social facts about people's ethical behavior and facts about how people reason in morals, and so on (cf. Myyrya, Juujärvi, and Pesso 2010). For instance, this could consist of learning about what opinion most people in some specific group in society have about some moral issue, such as recycling (Williams et al. 2008), or whether we ought to make research into using nuclear power (Cerutti 2010). Doing ethics in school could also consist of studying how teenagers consider electrical cars; whether young people are more positive to surveillance technology than older people, and so on. Hence, the DE approach would be best characterized as a sociological or descriptive approach to ethics (Copp 2006), and the goal of the school regarding ethics would then be teaching (or helping the students learn) social, statistical, psychological, or sociological facts about moral issues (cf. Albert 1957). 
(ii) The MF approach: According to the MF approach to ethics in school, which is frequently defended (Covell and Howe 2001), the aim of the school is to mediate to the students some pre-defined substantial values. The MF approach can be expressed in many different ways. The following statements will all, for the aims of this paper, be categorized as expressions of the MF approach: 'school has the obligation to foster or cultivate students into upholding the values of society,' (cf. Cookson 2001) 'school should teach students what is right or wrong,' or 'school should foster students into having some virtues like being caring or respectful to others or to perform certain actions (e.g. buying ecofriendly cars) or not perform certain actions (such as lying, posting private information about others on the Internet, or traveling excessively by airplane).' (cf. Berkowitz and Grych 1998; Mahowald 2004)

We use the term 'fostering' in a rather narrow sense in this article, as some kind of rather straightforward transmission of values. One could argue that all education is fostering in some sense. This would be using 'fostering' in a broader sense. Moreover, MF has similarities with what is sometimes called 'character education' (Althof and Berkowitz 2006; Winton 2008), but due to there being many rivaling definitions of character education (Davis 2003), we use the expression 'moral fostering.' It also has similarities with value education (Veugelers 2000) and moral education (Schuitema, ten Dam, and Veugelers 2008). As is evident in the writings of Sama and Shoaf (2008), MF is of relevance for many contexts, not only education. The idea of MF as one of the aims of education has very long roots in Western societies. Hogan (2010) states that these ideas are evident in Plato and Aristotle, and after that gained importance in the Roman empire, then for a long time was being upheld by the church's definition of education in terms of mediating religious doctrines, and thereafter being an important part of (sometimes secular) states' wishes to cultivate its young ones into nationalism, patriotism, utilitarianism, or liberalism, among other doctrines.

(iii) The PE approach: According to the PE approach to ethics in school, school should help students learn to reason about ethics and to be able to think critically about ethics. The aim is to help students evaluate different moral standpoints, to evaluate the strength of various arguments, to distinguish between different ways of ascribing value, and so on. Hence, according to the PE approach, the primary focus should not be set on learning what most people believe is right or on fostering students to accept some alleged set of values, but rather on reasons for holding something to be right; on arguments for whether this or that position is correct; on ways of critically examining moral positions and on thinking about ethics in a more independent way (Barrow 2010). If the PE approach was taken, ethics in school would consist in the students engaging in normative ethics and applied ethics, but to some extent also meta-ethics (Gewirth 1960, 1981; Sumner 1967). The idea of engaging is of great importance here because it is not so much a question of teaching students theories about normative ethics - which would rather be a question of having the DE approach - but rather of the students themselves doing normative ethics (or metaethics) in the sense of engaging in trying to answer the moral questions themselves, of scrutinizing different arguments and positions, and so on.

Given these distinctions, we can state three different theses, corresponding, respectively, to the three approaches. These could roughly be expressed as 'the students should learn DE in school,' 'there should be MF in school,' and 'the students should engage in PE in school.' 
Some consider the first two approaches (the DE and MF approaches) to be equivalent, for example those who think that ethical value depends on social facts in some way, like claiming that 'good' means the same as 'favored by the majority' (a form of meta-ethical naturalism), or that the good is determined in some other way by what the majority favors (some kind of relativism) or how the culture in question is formed (e.g. some kind of communitarianism). However, for some (e.g. skeptical realists), there would be no relevant connection at all. For this reason, we will remain neutral throughout the paper, and discuss the two approaches separately.

Indeed, questions can be raised regarding the relationship between the second and third approaches. It can be argued that MF depends on PE (Crawford 2001). On the other hand, it is questionable whether one could, in fact, practice PE without undergoing any MF. Is it not so, one could ask, that students need to be fostered in some way for a critical dialog to be fruitful, let alone possible? But this would still be some other kind of fostering than what the MF approach consists of. It would be some second-order, or meta-level, fostering, for example fostering students into regarding a critical dialog as meaningful, or appreciating the rules of conduct in such a dialog. However, this differs from fostering students into holding substantial moral beliefs or attitudes, such as that one ought to reduce one's emission of carbon dioxide, in that this fostering is what Lipman, Sharp, and Oscanyan $(1980,86)$ would call 'procedural' fostering. Hence, PE incorporates some MF, but it is second-order values that are promoted. Moreover, these values themselves can be, and reasonably ought to be according to the PE approach, discussed in the context of a critical discussion about ethics in school.

\section{Three arguments for ethics in school}

In this section, we present and critically discuss three arguments for incorporating ethics in school. In doing this, we consider their strengths given each approach to ethics in school, respectively. Each argument in its original form contains the ambiguous expression "ethics in school.' By making this more precise, in accordance with the three different approaches, respectively, three new arguments arise for each one of the original arguments. We began with three arguments, but will end up with nine. Each one of these 'new' arguments has the phrase 'ethics in school' changed for the more precise phrase favored by the corresponding approach. The approach that provides the strongest arguments is the most reasonable approach to ethics in school, as far as the evidence considered in this article goes. Still, we discuss the arguments as three arguments (instead of nine), grouping together the three different (and more precise) variants of each original argument. The arguments to be considered are the following three:

The socialization argument: The school has an obligation to foster students to become good citizens (Dill 2007). Ethics in school would benefit to this. Hence, we should have ethics in school.

The quality of life argument: The school has an obligation to help students to be able to live better lives or has an obligation to foster the students to become persons who act in a morally correct way (Rowe 2006). Ethics in school would benefit to this. Hence, we ought to have ethics in school.

The tool argument: The students' results in other subjects would improve if the students had ethics in school (compared to more of the same) (Lovat and Clement 2008). Hence, there should be ethics in school. 
Considering these three arguments, given each of the three approaches, respectively, we could illustrate the chain of reasoning in Table 1.

In evaluating each pair of argument and approach, corresponding to a numbered box in the table, we will use a scale of strength with the following five points: weak, rather weak, intermediate, rather strong, and strong.

It should be noted that one could provide other arguments for why there should be ethics in school than those discussed in this article, but at least these seem relevant, as we shall see below.

\section{The socialization argument}

This first argument focuses on the school educating students to becoming good (or wellfunctioning) citizens (Cookson 2001). ${ }^{4}$ The idea that school ought to educate students into being good citizens can be found in the writings of Dewey (1897) and Lipman (2003), among other philosophers of education. These interpretations are supported by others, such as Dill (2007), Riley and Welchman (2003), and Murris (2008). Moreover, Althof and Berkowitz $(2006,495)$ claim that '[a]ny democratic society must concern itself with the socialization of its citizens.' It is reasonable to hold that this ought to be done through education. Sheppard, Ashcraft, and Larson $(2011,69)$ also support this claim, in stating that '[g]iven the dynamic and responsive aspects of democracy and its historical symbiosis with education, it seems reasonable if not imperative for educators to continually consider how to more effectively foster the development of democratic citizens.'

The crucial step of the argument is the second premise, which is that ethics in school helps educating students to become better citizens. As mentioned above, one can ask what it means to be a good (or well-functioning) citizen, and in order not to get too far off the track with a more thorough investigation here, we can assume that it (at least for the time being in democratic countries) has something to do with embracing typically democratic values, such as caring for others (Winton 2008) and having what Rawls (1971) calls a sense of justice. Moreover, one can assume it to relate to intellectual skills needed among the citizens for democracy to function well, such as being able to form a coherent judgment or position and argue for it (Rawls 1971), being able to value others' arguments and taking a critical perspective (Lindop 1993), and similar skills (Hinton 2008; Portelli and Reed 1995). These skills are important also in making decisions involving technology, which are common to our life and times, both personally, as in, for example, deciding whether to select one technology or another when choosing a new consumer product (such as a smartphone, computer, and so on), and more collective choices such as a community vote on whether to invest in district heating.

It should be noted that the importance of the critical thinking skills mentioned above vary between different concepts of citizenship. For example, a defender of a libertarian

Table 1. The resulting 9 arguments.

\begin{tabular}{lccc}
\hline & DE approach & MF approach & PE approach \\
\hline Socialization argument & 1 & 2 & 3 \\
Quality of life argument & 4 & 5 & 6 \\
Tool argument & 7 & 8 & 9 \\
\hline
\end{tabular}


concept of citizenship would probably consider them more important than a defender of a communitarian concept of citizenship. Nonetheless, it seems fairly reasonable to consider them at least of some importance to the most common views on citizenship. Clemitshaw (2008) claims that modern conceptions of citizenship education have come to focus more on the development of critical skills and skills of participation than has been done before. He discusses one influential view on citizenship education as being defined under three headings: 'knowledge and understanding about becoming informed citizens, developing skills of enquiry and communication, and developing skills of participation and responsible action.' (Clemitshaw 2008, 143)

Let us evaluate the socialization argument in relation to our three approaches to ethics in school, in turn, starting with the DE approach. Students should, according to this approach, learn what people think about some moral matter: for example, what the majority of people in the world think about the regulation and evaluation of new technologies and what risks are accepted in the deployment of these (cf. Ferretti 2010; Papastephanou 2006), or what they think about moral matters relating to computers and the Internet (Bynum 2011; Joshi and Krag 2010) such as pirate copying and intellectual property rights. The DE approach to ethics in school seems unable to make the second premise reasonable: why should one become a better citizen by knowing descriptive propositions about others' moral values, such as, for example, whether or not the majority deems stem cell technology to be morally unacceptable? Could it not be so that the worst citizen, one who never votes or takes active part in public life whatsoever, has extremely broad knowledge of other people's values? $?^{5}$ Indeed, one can take part in societal activities, for instance, voting, as a very good citizen without having much interest in others' values, but being rather clear about one's own. There seems to be a weak connection, if one at all, between learning DE in school and citizenship. Hence, the DE approach renders the socialization argument rather weak.

Our second approach, the MF approach, seems to give rather strong support to the second premise. If one is successfully educated to holding certain values or judgments (of importance for society), it seems rather likely that one is also going to be a more wellfunctioning citizen, than if one did not accept those values. Yet again, this is presuming that the attempt to foster is actually successful, that the values are actually beneficial to society, and that the students did not already uphold those values or would come to uphold them in some other way if they had not been subjects to MF in school. However, there are other problems to this approach. One such problem is that the values, judgments, and abilities of centrality for democracy are not only such things as the judgment that all people are equal in value, or similar values that children might possibly be taught to uphold through MF. Also, abilities (or generic skills) (Collins and Halverson 2010; Mustakova-Possardt 2004) such as critical thinking, decision-making abilities, and abilities to form moral judgments are of importance to well-functioning citizenship according to many scholars, as we have seen. The MF approach, though, prescribes the mediation of substantial values and not directly development of thinking skills. At best, then, the MF approach gives a rather strong support to the socialization argument.

The third approach, the PE approach, seems even more capable of giving support to the second premise. Research shows that already at an early age, students develop skills such as those listed above, if they are engaged in philosophical dialogs (Kurfiss 1988; Vansieleghem 2005). Involvement in philosophical dialogs is a way of educating children to reflective citizenship (Tozzi 2009). The critical perspective taken within this approach 
is likely to promote the abilities of critical thinking needed for a democracy to function well (Cam 2009). Moreover, values of great centrality to democracy, such as respect for others' opinions and value, and a willingness to let them speak and to actually listen to them, are promoted by such dialogs (Trickey and Topping 2004). Sheppard, Ashcraft, and Larson $(2011,79)$, in reviewing some recent research literature on citizenship education, conclude that it is not surprising to find a wealth of research which suggests that classroom discussions of controversial issues are powerful tools for fostering more active citizenship.' More or less controversial issues are a main starting point for a philosophical dialog about ethics in school. Fisher claims that 'there is no better preparation for being an active citizen in a democracy than for a child to participate with others in a community of enquiry founded on reasoning, freedom of expression and mutual respect.' $(2001,73)$ Given what has been said above, and that the dialogs are indeed successful, it seems reasonable to believe that if students learn ethics in the PE approach sense, they are likely to become well-functioning, active citizens. Thus, when considering this argument, it seems that the third approach is very successful. The PE approach renders the socialization argument strong.

\section{The quality of life argument}

The second argument resembles the socialization argument, but they are distinct. It takes stock from the idea that school ought to engage in increasing the welfare or quality of life of the students. These two ideas often occur together, but we hold them to be distinct for reasons beside the core of this paper. It has been stated, for example by Dewey (1897), that school has a duty or obligation to educate students in a way that helps them to live better lives. $^{6}$ This can be expressed in the way that the school has an obligation to educate students to become persons who act morally correctly, or more morally correctly than they would otherwise have acted (Covell and Howe 2001). Winch $(2010,174)$ states that it has 'traditionally, and rightly, been thought that education is a preparation for a worthwhile life.'

The next step in the argument is the premise that ethics in school would promote this goal, that is, educating students to live better lives. The conclusion of the argument is that there ought to be ethics in school.

This argument seems intuitively promising. Again, the first premise, that an important aim for education is to help students live better lives, is rather uncontroversial. It seems that the weak link might be the second step, the supposition that having ethics in school would benefit to this goal. This is analogous to the socialization argument discussed above.

Let us now discuss to what extent each approach is able to make sense of this argument, starting with the DE approach. In this sense of having ethics in school, the second step in the argument seems to be problematic. Why would learning about other people's moral behavior, beliefs, attitudes, or something similar lead to one living a better life ? $^{7}$ It is other things than knowing what other people think, it seems, that is important for me to be living a good life; important are such things as my ability to identify, and thereby being able to effectively and consciously pursue, my own aims and goals, the ability to form a judgment about what a good life is, and the like. But this does not have very much to do with the DE approach. But there could be indirect connections. For example, knowing how other people value things might help one get by in life (being too different from others might be troublesome). However, this is only indirect, and still depends on one 
knowing what to do with this insight. Dealing with ethics in accordance with the DE approach does not provide this. Hence, the quality of life argument seems weak given the DE approach.

The second approach is the MF approach, holding that the school should aim at fostering the students to become better persons, in a moral sense. This approach, in contrast with the first, seems to give a rather strong support to the second step in the argument (cf. Covell and Howe 2001). In this sense of practicing ethics in school, it seems likely that the school will promote the moral aspects of the students' lives, given that the school succeeds in its undertakings (which we will relate to below, in discussing the tool argument and the MF approach). However, we can note already that there are reasons for being skeptical as to whether the MF approach to ethics in school can actually bring about the kind of learning that promotes quality of life (Rowe 2006). Other arguments for this position comes from Dewey, who thinks that values themselves are not given, but are experimental outcomes of inquiry (Semetsky 2009), and Smith, who holds that ethical matters has a 'dialogic and tentative nature,' never being 'conclusively settled.' (2011, 178) There always have to be elements of inquiry about and redefining of values, then, and that speaks in disfavor of the MF approach in its rigid and top-down view of morality. To conclude, the MF approach renders the quality of life argument intermediate.

The third approach, the PE approach, interprets ethics in school as a discursive and critical undertaking, where students are encouraged to examine their own as well as other moral standpoints and actions, giving arguments for and against them, and trying to build up an ethical awareness. For this approach, the second step in the argument seems reasonable; the premise seems correct. One of the things to be discussed in such ethical dialogs would be what quality of life is, and how one lives a good life. Hence, if school aims at helping the students develop an ability to evaluate and form these kinds of judgments, then it seems that the students, if school succeeds, are more capable of living morally good lives. For example, Merry $(2007,55)$ argues that

the well-being of the child is paramount and [...] one of the best ways to promote a child's well-being is to provide an education likely to promote autonomy so that children may eventually be enabled to pursue their own conception of the good.

This position could be further strengthened by Smith's (2011) noting that ethics has a dialogic and tentative nature, constantly open for further elaboration and redefinition. Developing autonomy of thinking is one of the benefits of doing PE. Moreover, it has been argued, for example by Tozzi (2009), that practicing PE helps children to deal with difficult issues and that it has a therapeutic virtue. Also, there are reasons to believe that engaging in PE is a good means to fulfill certain personal potentialities (cf. Murris 2008), which seems reasonable to consider connected to living a good life. ${ }^{8}$ Moreover, studies have shown that students engaged in such dialogs gain in self-esteem and emotional growth (Trickey and Topping 2004).

An important aspect of living a good life related to ethics in school seems to be the ability of making good choices in one's life, like choices regarding technology and technology use. ${ }^{9}$ Such choices could include choices concerning mostly oneself, such as whether or not to invest in the most recent technology in a certain field, choices with consequences for others or our shared world, such as what technological products to consume with regard to their social or environmental influence, or choices between possible political resolutions about technology and technology use. Schools should help 
students develop these abilities, and the PE approach seems most promising in realizing the aim of helping students develop the decisional abilities needed for these endeavors. Semetsky $(2009,78)$ also gives support to the PE approach when saying that '[1]earning what to do and how to behave implies decision-making and choosing intelligently and ethically between alternatives.' She continues by drawing educational implications of this: 'The need for developing a sense of value judgements - rather than simply learning a given set of values - is what moral education should focus on.' (Semetsky 2009, 78) Indeed, this seems to give a better support to the argument in question. Hence, we can conclude that the PE approach renders the quality of life argument strong.

\section{The tool argument}

The third argument differs slightly from the above two, in focusing on the students' abilities to learn other subjects better through ethics in school, which is discussed by Lovat and Clement (2008). The argument can be stated as follows: if one learns ethics and ethical abilities, one is more likely to succeed in learning other things, such as other subjects in school. Hence, there should be ethics in school.

The DE approach seems unable, once again, to render this argument strong. It seems that learning facts about the behavior of others does not have any direct implications on the learning of other school subjects in general. However, it might have some specific impact on, for instance, social studies. This gives a weak support for the argument, being a general argument, not specifically about social sciences.

The second approach, the MF approach, also seems rather toothless in rendering this argument reasonable. Of course, one can argue that if students are fostered to do their best and to work hard and pay attention to what goes on in school (and so on), then their learning, in general, may be benefited. However, this is problematic for at least three reasons. The first is that the student can always 'resist' the fostering, possibly as a consequence of feeling pushed or forced by the school to act or think in a certain way. The second is that even if the students are fostered in the way that school aims to foster them, it is possible that other influences 'foster them' differently by having an impact on them in another direction. The third problem is that the traits at stake seem difficult to acquire through fostering, at least in a sustainable and long-term sense. Moreover, an important part of how ethics could benefit the learning of other subjects is by helping the students acquire critical thinking and enquiry (Dill 2007; Lovat and Clement 2008), and that means that they ought not to accept whatever people try to foster upon them, so to speak. Hence, it is hard to see how one can be fostered or forced into critical thinking. An analogy would be that it seems hard to force someone to resist force. Moreover, there are reasons to believe that these positive character traits are best defended by, and upheld by, the students if they actually have reasons for acting as they do, and are not only fostered into doing so. Hence, the second approach does not seem very successful in rendering the argument strong, and therefore gets a rather weak valuation.

The third approach, on the other hand, seems able to give support to this argument as well. Educating in ethics in this sense, the critical and evaluative sense, seems likely to benefit learning in general, because students, according to many studies and as reviewed by Trickey and Topping (2004), acquire important abilities such as critical thinking, logical thinking, as well as argumentative and evaluative skills, which are of importance for learning in general. ${ }^{10}$ For example, developing critical thinking and logical thinking 
Table 2. Summary of the respective strengths of the 9 arguments.

\begin{tabular}{llll}
\hline & DE approach & MF approach & PE approach \\
\hline Socialization argument & Rather weak & Rather strong & Strong \\
Quality of life argument & Weak & Intermediate & Strong \\
Tool argument & Weak & Rather weak & Strong \\
\hline
\end{tabular}

can benefit learning in technological and scientific subjects. Research has shown that philosophical dialog at an early age has positive impacts on, for instance, problem-solving skills and logical reasoning skills (Trickey and Topping 2004), which in turn is needed for mathematical thinking and reasoning (Sibley 2009) which are applied in technology. Hence, this argument seems strong if we understand ethics in school in accordance with the PE approach.

To sum up what has been said about the three (nine) arguments so far, we insert the results obtained from the reasoning above in another table, Table 2.

The evaluation shows that these arguments best support the PE approach to ethics in school. Every argument is stronger given the PE approach than given any other approach. And every argument is stronger given the MF approach than given the DE approach.

\section{Concluding remarks}

The three arguments discussed in this paper are strongest, and strong, if 'ethics in school' is interpreted as PE. Therefore, we have three strong arguments in favor of the PE approach, and less strong arguments in favor of the MF approach and the DE approach. This suggests that we should have PE in school, in technology education, and in general, and also more so than DE or MF. However, this does not imply that we should not have ethics in school in the other forms as well. For example, as we have seen, there might be reasons for having some MF in school. Moreover, it should be noted that it might be possible to give other strong arguments on the topic, some which would give reasons for other conclusions. Hence, further research in these matters is of great importance and interest. Nonetheless, the arguments considered in this article give us reasons to hold PE to be the most important of these three different approaches to ethics in school.

\section{Notes}

1. Email: eva.alerby@1tu.se

2. Email: anders.persson@1tu.se

3. We use the expression 'ethics in school' in a broad sense, meaning all those things in the educational aspects of school that regard ethics, such as activities in class, teachers' lectures, students' writing assignments, and so on. The approaches presented above are to be considered as regarding all of this. Hence, it does not directly follow anything about, for example, ways of structuring the teaching from any of those approaches in school. Therefore, we are not directly discussing in what pedagogical or didactical forms ethics should be dealt with, but rather what content should be in focus, and what fundamental approach to take with regard to this content.

4. We are not making any substantial assumptions regarding what a good citizen would be. The only assumption regarding these matters, in order for the argument to be at all reasonable for consideration, is that it is meaningful to think of such a concept as good (and less good) citizens, better or worse citizens, or more or less well-functioning citizens, or something similar. We do not wish here to take a standpoint on which of these is more reasonable. 
5. Maybe this broad knowledge is connected to why the person does not contribute to society; he or she might spend all his or her time learning to memorize statistics about public life and opinions.

6. Note that we are not making any substantial claims about what a better life would consist of. What merely needs to be assumed in order for this argument to be comprehensible is that there exist such things as a good life and a not-so-good life, or that lives could be compared to each other in terms of how good they are in some sense, or something similar to this. It does not necessarily have to be an interpersonal comparison; it is rather more intuitive, in this case, to think of an intrapersonal comparison, i.e. a comparison between the different possible lives of one person. One such way of ranking different lives would be to say that the person whose lives are to be compared would choose one rather than the other. To assume that such comparisons can be made seems fairly uncontroversial (cf. Parfit 1984; Rawls 1971).

7. Once again, if one holds some kind of communitarianism, relativism or variant of naturalism where rightness is defined by, or depends on, the views of (some group of) people, this connection would be strong, given that the students also would choose to act in accordance with their beliefs about other people's moral judgments. But these are particular views on meta-ethics, upheld by some, and other meta-ethicists would disagree; hence, this connection cannot be taken to be strong, because it relies on these substantial claims in meta-ethics (at least until we are certain that these claims are correct would they be so).

8. This, of course, hinges on some substantial assumptions on what it is to live a good life.

9. This is the expression of a substantial assumption about what it is to be living a good life. However, it is a fairly uncontroversial one, we believe, since the only thing assumed here is that the possibility of making good choices (in some sense) in life benefits in making one's life good or better. If this assumption is questioned, then the whole paragraph is questioned, because it rests rather heavily on this assumption. However, the main point of this section does not depend solely on this paragraph.

10. It should be pointed out that other subjects might also develop these abilities. However, as long as students are further benefited by dealing with ethics according to the PE approach, this is enough for our argument here and this condition seems met.

\section{References}

Albert, E. M. 1957. "Value Sentences and Empirical Research.” Philosophy and Phenomenological Research 17 (3): 331-338.

Althof, W., and M. W. Berkowitz. 2006. "Moral Education and Character Education: Their Relationship and Roles in Citizenship Education." Journal of Moral Education 35 (4): 495-518.

Barrow, W. 2010. "Dialogic, Participation and the Potential for Philosophy for Children." Thinking Skills and Creativity 5 (2): 61-69.

Berkowitz, M. W., and J. H. Grych. 1998. "Fostering Goodness: Teaching Parents to Facilitate Children's Moral Development." Journal of Moral Education 27 (3): 21.

Bynum, T. 2011. "Computer and Information Ethics." In The Stanford Encyclopedia of Philosophy. Spring 2001 ed., edited by E. N. Zalta, 1-34. http://plato.stanford.edu/archives/spr2011/entries/ ethics-computer/

Cam, P. 2009. "Educating for Democracy." Diogenes 56 (4): 37-48.

Cerutti, F. 2010. "Defining Risk, Motivating Responsibility and Rethinking Global Warming." Science and Engineering Ethics 16: 489-499.

Clemitshaw, G. 2008. "Citizenship without History? Knowledge, Skills and Values in Citizenship Education." Ethics and Education 3 (2): 135-147.

Collins, A., and R. Halverson. 2010. "The Second Educational Revolution: Rethinking Education in the Age of Technology." Journal of Computer Assisted Learning 26 (1): 18-27.

Cookson, P. W. 2001. "Fostering Moral Democracy." Educational Leadership 59 (2): 42-45.

Copp, D. 2006. The Oxford Handbook of Ethical Theory. New York: Oxford University Press.

Covell, K., and R. B. Howe. 2001. "Moral Education through the 3 Rs: Rights, Respect and Responsibility." Journal of Moral Education 30 (1): 29-41. 
Crawford, P. D. 2001. "Educating for Moral Ability: Reflections on Moral Development Based on Vygotsky's Theory of Concept Formation." Journal of Moral Education 30 (2): 113-129.

Davis, M. 2003. "What's Wrong with Character Education?" American Journal of Education 110 (1): $32-57$.

Dewey, J. 1897. "My Pedagogic Creed." School Journal 54 (January): 77-80.

Dill, J. S. 2007. "Durkheim and Dewey and the Challenge of Contemporary Moral Education." Journal of Moral Education 36 (2): 221-237.

Ferretti, M. P. 2010. "Risk and Distributive Justice: The Case of Regulating New Technologies." Science and Engineering Ethics 16: 501-515.

Fisher, R. 2001. "Philosophy in Primary Schools: Fostering Thinking Skills and Literacy." Reading 35: 67-73.

Frey, R. G., and C. H. Wellman. 2003. A Companion to Applied Ethics. Malden, MA: Blackwell.

Fuchs, C., R. M. Bichler, and C. Raffl. 2009. "Cyberethics and Co-operation in the Information Society." Science and Engineering Ethics 15: 447-466.

Gewirth, A. 1960. "Meta-Ethics and Normative Ethics." Mind 69 (274): 187-205.

Gewirth, A. 1981. "The Future of Ethics: The Moral Powers of Reason." Nous 15 (1): 15-30.

Hinton, R. 2008. "Children's and Young People's Participation in Public Decision-Making." The International Journal of Children's Rights 16 (3): 281-284.

Hogan, P. 2010. "Preface to an Ethics of Education as a Practice in its Own Right." Ethics and Education 5 (2): 85-98.

Johnson, S. 2009. "The Era of Nanomedicine and Nanoethics: Has It Come, Is It Still Coming, Or Will It Pass Us By?" The American Journal of Bioethics 9 (10): 1-2.

Joshi, M., and S. S. Krag. 2010. "Issues in Data Management." Science and Engineering Ethics 16: $743-748$.

Kurfiss, J. G. 1988. Critical Thinking: Theory, Research, Practice, and Possibilities. Washington, DC: Association for Study of Higher Education.

Lindop, C. 1993. "Critical Thinking and Philosophy for Children: The Educational Value of Philosophy." In Thinking Children and Education, edited by M. Lipman, 676-681. Dubuque, IA: Kendall/Hunt.

Lipman, M. 2003. Thinking in Education. Cambridge: Cambridge University Press.

Lipman, M., A. M. Sharp, and F. S. Oscanyan. 1980. Philosophy in the Classroom. Philadelphia, PA: Temple University Press.

Lovat, T., and N. Clement. 2008. "Quality Teaching and Values Education: Coalescing for Effective Learning." Journal of Moral Education 37 (1): 1-16.

Mahowald, M. B. 2004. "Self-Preservation: An Argument for Therapeutic Cloning, and a Strategy for Fostering Respect for Moral Integrity." American Journal of Bioethics 4 (2): 56-66.

Merry, M. S. 2007. "The Well-being of Children, the Limits of Paternalism, and The State: Can Disparate Interests be Reconciled?" Ethics and Education 2 (1): 39-59.

Murris, K. S. 2008. "Philosophy with Children, the Stingray and the Educative Value of Disequilibrium." Journal of Philosophy of Education 42 (3-4): 667-685.

Mustakova-Possardt, E. 2004. "Education for Critical Moral Consciousness." Journal of Moral Education 33 (3): 245-269.

Myyrya, L., S. Juujärvi, and K. Pesso. 2010. "Empathy, Perspective Taking and Personal Values as Predictors of Moral Schemas." Journal of Moral Education 39 (2): 213-233.

Papastephanou, M. 2006. "Education, Risk and Ethics." Ethics and Education 1 (1): 47-63.

Parfit, D. 1984. Reasons and Persons. Oxford: Clarendon Press.

Portelli, J. P., and R. F. Reed, eds. 1995. Children, philosophy, and democracy. Calgary: Detselig Enterprises Cop.

Rawls, J. 1971. A theory of justice. Cambridge, MA: Harvard University Press.

Riley, P., and J. Welchman. 2003. "Rousseau, Dewey, and Democracy." In Companion to the Philosophy of Education, edited by R. Curren, 94-112. Oxford: Blackwell.

Rowe, D. 2006. "Taking Responsibility: School Behaviour Policies in England, Moral Development and Implications for Citizenship Education." Journal of Moral Education 35 (4): 519-531.

Sama, L. M., and V. Shoaf. 2008. "Ethical Leadership for the Professions: Fostering a Moral Community." Journal of Business Ethics 78: 39-46. 
Schuitema, J., G. ten Dam, and W. Veugelers. 2008. "Teaching Strategies for Moral Education: A Review." Journal of Curriculum Studies 40 (1): 69-89.

Semetsky, I. 2009. "Continuities, Discontinuities, Interactions: Values, Education, and Neuroethics." Ethics and Education 4 (1): 69-80.

Sheppard, S., C. Ashcraft, and B. Larson. 2011. "Controversy, Citizenship, and Counterpublics: Developing Democratic Habits of Mind." Ethics and Education 3 (2): 121-134.

Sibley, T. Q. 2009. Foundations of Mathematics. Hoboken: Wiley.

Smeds, G. 2008. "Parenting in a Technological Age." Ethics and Education 6 (2): 171-180.

Smith, R. 2011. "On Dogs and Children: Judgements in the Realm of Meaning." Ethics and Education 6 (2): 171-180.

Stovall, P. 2011. "Professional Virtue and Professional Self-Awareness: A Case Study in Engineering Ethics." Science and Engineering Ethics 17: 109-132.

Sumner, L. W. 1967. "Normative Ethics and Metaethics." Ethics 77 (2): 95-106.

Tozzi, M. 2009. "Helping Children To Philosophizing: State of the Art, Live Issues, Outcomes and Proposals." Diogenes 56 (4): 49-60.

Trickey, S., and K. J. Topping. 2004. "Philosophy for Children: A Systematic Review." Research Papers in Education 19 (3): 365-380.

Vansieleghem, N. 2005. "Philosophy for Children as the Wind of Thinking." Journal of Philosophy of Education 39 (1): 19-35.

Veugelers, W. 2000. "Different Ways of Teaching Values." Educational Review 52 (1): 37-46.

Williams, E., R. Kahhat, B. Allenby, E. Kavazanjian, J. Kim, and M. Xu. 2008. "Environmental, Social, and Economic Implications of Global Reuse and Recycling of Personal Computers." Environmental Science \& Technology 42 (17): 6446-6454.

Winch, C. 2010. "Learning the Virtues at Work." Ethics and Education 5 (2): 173-185.

Winton, S. 2008. "The Appeal(s) of Character Education in Threatening Times: Caring and Critical Democratic Responses." Comparative Education 44 (3): 305-316. 